\title{
"I'm going to push this door open. You can close it.": The brokering work of oncology nurses in the introduction of early palliative care
}

Shan Mohammed RN PhD ${ }^{1}$, Camilla Zimmermann MD PhD $1,2,3,4,5$, Pamela Savage RN MAEd ${ }^{5}$

${ }^{1}$ Department of Supportive Care; ${ }^{2}$ Division of Medical Oncology and Hematology, Department of Medicine, University of Toronto; ${ }^{3}$ Department of Psychiatry; ${ }^{4}$ Campbell Family Cancer Research Institute; ${ }^{5}$ Princess Margaret Cancer Centre, University Health Network, Toronto, Ontario, Canada

\section{BACKGROUND}

In early palliative care (EPC), palliative supports and resources are provided at an earlier stage in the treatment trajectory. ${ }^{1} \mathrm{EPC}$ is associated with improved symptom burden, better quality of life, and the decreased incidence of aggressive oncological treatments. ${ }^{2,3}$ Several oncologist-related factors may act as barriers to EPC, including late referral to palliative care, discomforts with discussing death, and lack of time. ${ }^{4}$ Little empirical and conceptual consideration, however, has been given to how the roles and responsibilities of oncology nurses might impact the provision of EPC. By working with seriously ill cancer patients, who are often yet to referred to palliative care, oncology nurses may play a pivotal role in ensuring the success of EPC as an emerging model of care delivery.

\section{OBJECTIVES}

The broader aims of this study were threefold: (1) To examine the roles and responsibilities of nurses in the provision of EPC, and also to identify the barriers and/or facilitators they may encounter in this regard; (2) To explore nurses' perceptions and beliefs about EPC within their practice; (3) To explore how nurses' interactions with the healthcare team and position within the cancer care system might shape nursing practice within EPC. For this poster, we focused on the roles and responsibilities of nurses in the provision of EPC and explored some of the barriers and facilitators they encountered.

\section{REFERENCES}

Bruera, E., \& Hui, D. Integrating supportive and palliative care in the trajectory of cancer: establishing goals and models of care. Journal of Clinical Oncology. 2010; 28(25): 4013-4017. Zimmermann, C., Swami, N., Krzyzanowska, M., Hannon, B., Leighl, N., Oza, A., ... \& Lo, C. Early palliative care for patients with advanced cancer: a cluster-randomised controlled tria The Lancet. 2014; 383(9930): 1721-1730.

Temel, J., Greer, J., Muzikansky, A., Gallagher, E., Admane, S. Jackson V., et al. Early palliative care for patients with metastatic non-small-cell lung cancer. The New England Journal of Medicine. 2010; 363: 733-742.

Wentlandt, K., Krzyzanowska, M. K., Swami, N., Rodin, G. M., Le, L. W., \& Zimmermann, C. Referral practices of oncologists to specialized palliative care. Journal of Clinical Oncology. 2012; 30(35): 4380-4386.

Charmaz, K. Constructing grounded theory. Thousand Oak, CA: Sage publications. 2014.

\section{METHOD}

Constructivist grounded theory guided our methods and analysis. In this approach, the investigator and participant co-construct the data as a product of the research process. ${ }^{5}$ We recruited nurses from several ambulatory care oncology clinics in a tertiary cancer hospital in Ontario, Canada. Nurses participated in semistructured interviews (in-person and on the telephone). Data analysis ran concurrently with data collection. Coding was guided by constant comparison, which generated abstract concepts through the inductive and iterative processes of comparing codes with data. Analysis took place until theoretical saturation was achieved.

\section{RESULTS}

\begin{tabular}{|c|c|}
\hline DEMOGRAPHIC INFORMATION & $\begin{array}{l}\text { NURSES }(\mathrm{N}=20) \\
\mathrm{N}(\%)\end{array}$ \\
\hline Age, Median (Range) & $35-44$ \\
\hline \multicolumn{2}{|l|}{ Gender } \\
\hline Female & $18(90 \%)$ \\
\hline Male & $2(10 \%)$ \\
\hline \multicolumn{2}{|l|}{ Education } \\
\hline Masters & $13(65 \%)$ \\
\hline Bachelors & $5(25 \%)$ \\
\hline Diploma & $2(10 \%)$ \\
\hline $\begin{array}{l}\text { Years Spent as a Nurse, Median } \\
\text { (Range) }\end{array}$ & $20(6-37)$ \\
\hline Years Spent as a Nurse in & $15(1-36)$ \\
\hline \multicolumn{2}{|l|}{ Oncology, Median (Range) } \\
\hline \multicolumn{2}{|l|}{ Years Spent as a Nurse in the } \\
\hline Study Setting, Median (Range) & $11(1-34)$ \\
\hline \multicolumn{2}{|l|}{ Current Clinical Position } \\
\hline Nurse Practitioner & $10(50 \%)$ \\
\hline Staff Nurse & $6(30 \%)$ \\
\hline Clinical Nurse Specialist & $2(10 \%)$ \\
\hline Other Advanced Practice & $2(10 \%)$ \\
\hline \multicolumn{2}{|l|}{ Current Areas of Practice } \\
\hline Breast & $6(30 \%)$ \\
\hline Hematology & $4(20 \%)$ \\
\hline Chemotherapy Day Care & $3(15 \%)$ \\
\hline Head and Neck & $3(15 \%)$ \\
\hline Bone Marrow Transplant & $2(10 \%)$ \\
\hline Pancreatic & $1(5 \%)$ \\
\hline Wound Care & $1(5 \%)$ \\
\hline
\end{tabular}

\section{CONCLUSION}

Oncology nurses play a central role by brokering EPC. They draw on their proximity to patients, relational and communication capabilities, care coordination skills, and advocacy abilities. Brokering work is conditional on nurses' comfort level, experience, workload, and relationships with other healthcare professionals. This work must be enacted within the boundaries of the nursing role and their "in between" position within the team.

\section{STUDY CATEGORIES}

The core category BROKERING PALLIATIVE CARE includes three subcategories:

\section{MOVING BACKWARDS AND \\ FORWARD}

Stepping back to assess patients' willingness to hear about EPC and then proceeding by selling the benefits of palliative to improving everyday function.

"'And I can tell clearly if I can't go there and I won't go there, because I know it's not going to go over very well. Sometimes I also just say, 'I'm going to push this door open. You can close it and tell me to shut down.' So, I give them permission to shut me right down." (RN10, Clinical Nurse Specialist, Pancreatic Clinic)

\section{TACKLING MISCONCEPTIONSAND STIGMA}

Dealing with patients' assumptions about palliative care as diminishing hope and accelerating the end of life.

“They [patients] don't want to hear palliative care. I find I had a role to explain, at least my understanding of how palliative care worked in this setting, which can be different from other lay meanings of the word. Just as it was about symptom management or supportive care or whatever language you want to use rather than end of life..." (RN19, Advanced Practice Nurse, Wound

\section{ADVOCATING WITH THE INTERPROFESSIONALTEAM}

Bringing patient concerns forward to the team, managing interprofessional dynamics, and seeding the process of referral to EPC.

“... I don't have to do that because they know me very well. Like I'll just say, 'So and so needs pain and symptom.' 'Okay, sure.' Like, that's what it is. I don't even have to sit there and say, 'The pain is so bad and blah, blah, blah or whatever.' I do have to sell it for some physicians who, you know, are maybe, what's the nicest way of saying this... I just feel like some physicians want to control everything." 